\title{
ORIGINAL ARTICLE \\ The spinal cord independence measure (SCIM)-III self report for youth
}

\author{
MJ Mulcahey ${ }^{1}$, CL Calhoun ${ }^{1}, \mathrm{R}$ Sinko $^{1}, \mathrm{EH} \mathrm{Kelly}^{2,3}$ and LC Vogel ${ }^{2,4}$
}

Study design: The items and response scales of the Spinal Cord Independence Measure (SCIM-III) self report (SR) were exposed to formal cognitive testing with children with $\mathrm{SCl}$, and in parallel a survey using the modified Delphi Technique was conducted to engage content experts in an iterative critical review of the SCIM-III SR.

Objectives: To evaluate the validity of the SCIM-III SR for pediatric utilization.

Setting: United States of America.

Methods: Formal cognitive testing was conducted with 17 youths with SCI and required them to read and answer each SCIM-III SR item aloud. Think aloud methodology was used to record details about how youths understood and interpreted items and why they selected a given response. The interviews were audiotaped and transcribed verbatim. Content analysis focused on identifying words that children could not read or understand. In parallel, the Modified Delphi Technique engaged expert therapists to critically review the SCIM-III SR for pediatric utilization.

Results: Every SCIM-III SR item and response scale required modification before children were able to read, understand and respond to them. Youth encountered difficulties because of vague terms, medical jargon and complex words and phrases. Three iterative Delphi rounds were required before achieving $80 \%$ agreement that items and response scales were written well for children.

Conclusion: Our findings informed modifications to every SCIM-III SR item and response scale, producing a pediatric version of the tool that we formally refer to as the SCIM-III SR-Youth (SCIM-III SR-Y).

Sponsorship: The study was funded by the Craig H Neilsen Foundation, Spinal Cord Injury Research on the Translation Spectrum, Senior Research Award \#282592 (Mulcahey, PI).

Spinal Cord (2016) 54, 204-212; doi:10.1038/sc.2015.103; published online 16 June 2015

\section{INTRODUCTION}

The Spinal Cord Independence Measure $(\text { SCIM-III })^{1}$ has gained recognition as a relevant outcomes instrument in spinal cord injury (SCI) and one that is recommended for use in SCI clinical trials. ${ }^{2}$ The SCIM-III is a 'disease-specific' instrument that contains items that evaluate self-care, respiration, bladder and bowel management and mobility. Three large-scale adult studies ${ }^{3-5}$ established moderate-tostrong reliability and validity and showed that when compared with the FIM (Functional Independence Measure) the SCIM-III had broader content range and was more responsive to change. Additional work has examined clinically important differences in SCIM-III scores, ${ }^{6}$ established target values for neurological levels in complete $\mathrm{SCI}^{7}$ and has validated a self-report version. ${ }^{8}$ The self-report version offers a practical alternative to the performance-based version, especially in community-based centers and for longitudinal monitoring.

The content of the SCIM-III is highly relevant for children with SCI as pediatric rehabilitation focuses on restoring capabilities for self-care and mobility, as appropriate for age and development. ${ }^{9}$ Children as young as 6 years of age learn to manage their bladder and begin to participate in their bowel program. ${ }^{10}$ Children with SCI are taught skills for independent dressing, body transfers and upright and wheeled mobility. ${ }^{9}$ Current instruments to evaluate treatment outcomes on self-care and mobility have ceiling and floor effects and gaps in content when used with children with SCI. ${ }^{11}$ Although one way to address the limitations of outcomes instruments in pediatrics is to develop new instruments, the preferred way, where appropriate, is to establish the lower age limit for existing instruments that are robust and already in the field. Given the relevance of the SCIM-III content to pediatric SCI and its endorsement for use in adult SCI clinical trials, ${ }^{2}$ it is prudent to systematically examine the psychometric properties relevant to its utilization with youth.

\section{MATERIALS AND METHODS}

Mixed methods were used to evaluate the SCIM-III self report (SR). Specifically, SCIM-III SR items and response scales were exposed to formal cognitive testing with children with SCI, and in parallel a survey using the modified Delphi technique was conducted to engage content experts in an iterative critical review of the SCIM-III SR.

\section{Cognitive testing}

Cognitive testing ensures that items and response scales are written in a way that conveys their intent clearly, without complex words, medical jargon and ambiguity. ${ }^{12}$ Because the goal of this study was to evaluate reading and

${ }^{1}$ Department of Occupational Therapy, Jefferson School of Health Professions, Thomas Jefferson University, Philadelphia, PA, USA; ${ }^{2}$ Shriners Hospitals for Children, Chicago, IL, USA; ${ }^{3}$ Marquette University, Milwaukee, WI, USA and ${ }^{4}$ Rush Medical College, Chicago, IL, USA

Correspondence: Dr MJ Mulcahey, Department of Occupational Therapy, Jefferson School of Health Professions, Thomas Jefferson University, 901 Walnut Street, 6th Floor (642), Philadelphia, PA 19107, USA.

E-mail: maryjane.mulcahey@jefferson.edu

Received 18 March 2015; revised 10 May 2015; accepted 12 May 2015; published online 16 June 2015 
comprehension of SCIM-III SR items in youths with SCI, purposeful sampling recruited youths from one pediatric SCI program in the United States. We enrolled youths aged 7-16 with SCI of at least 3-month duration. Another enrollment requirement was that youths had to have finished their initial episode of rehabilitation and discharged to home. Parent and child consent and assent were obtained prior to study enrollment.

We employed techniques used in previous studies ${ }^{13,14}$ such that every SCIM-III SR item and response scale were exposed to cognitive testing. Subjects were asked to read and answer each item aloud, using the response scale choices. Think aloud methodology ${ }^{15}$ was used to record details about how children understood and interpreted items and why they selected a given response. After each child participant read and answered each question, they responded to these questions: 'In your words, tell me what this question is asking you' and 'Using your own words, how would you ask this question to a friend?'. Open-ended questions were used to further appreciate the child's understanding about items and response scale choices. The interviews, which were performed by one of two occupational therapists (OT) or by a physical therapist (PT), were conducted in a private room, audiotaped and transcribed verbatim. Content analysis focused on identifying replacement words and phrases suggested by children. The findings were used to modify the items and response scales for round 2 and 3 of the Modified Delphi Survey.

\section{Modified delphi survey}

The Modified Delphi Technique ${ }^{16}$ was used to develop consensus on the appropriateness of the content, structure and wording of SCIM-III SR items and response scales for child SR. Three questions for each of the SCIM-III items were presented to expert therapists using an internet-based survey: 'Is the content of this item appropriate for children?'; 'Is this item written well for children?'; and 'Is this response scale written well for children?'. For any 'no' response, therapists provided a rationale for their answer and suggested alternative wording or phrases. The modified Delphi survey was performed iteratively until $80 \%$ agreement was achieved for each of the three questions, for each of the 17 SCIM-III SR items.

E-mail invitations were sent to known pediatric SCI therapists asking them to participate in the survey (purposeful sampling) and to forward the e-mail invitation to their colleagues in pediatrics, pediatric SCI rehabilitation or adult SCI rehabilitation (snowball sampling). The e-mail invitations included a

Table 1 Subject characteristics in cognitive testing sample

\begin{tabular}{|c|c|c|c|c|c|c|c|}
\hline $\begin{array}{l}\text { Age }^{\mathrm{a}} \text { at } \\
\text { cognitive } \\
\text { interview }\end{array}$ & $\begin{array}{l}\text { Time }^{a} \\
\text { since } \\
\text { injury }\end{array}$ & $\begin{array}{l}\text { Last grade } \\
\text { completed }\end{array}$ & Sex & Race & Ethnicity & $N L$ & $A / S$ \\
\hline 7 & 1 & 2 & $M$ & C & $\mathrm{NH}$ & C4 & $\mathrm{D}$ \\
\hline 8 & 1 & 1 & $M$ & C & $\mathrm{NH}$ & $\mathrm{C} 8$ & $A$ \\
\hline 8 & 8 & 1 & $M$ & C & $\mathrm{NH}$ & UN (tetraplegia) & UN \\
\hline 9 & 2 & 3 & $\mathrm{~F}$ & C & $\mathrm{NH}$ & T9 & $A$ \\
\hline 9 & 3 & 3 & $M$ & C & $\mathrm{H}$ & C6 & B \\
\hline 10 & 5 & 4 & M & C & $\mathrm{NH}$ & L1 & $A$ \\
\hline 11 & 7 & 5 & M & C & $\mathrm{NH}$ & c6 & $A$ \\
\hline 12 & 4 & 5 & $\mathrm{~F}$ & C & $\mathrm{NH}$ & $\mathrm{C} 2$ & $\mathrm{D}$ \\
\hline 12 & 10 & 5 & $\mathrm{~F}$ & C & $\mathrm{NH}$ & T10 & $C$ \\
\hline 12 & 5 & 6 & M & C & $\mathrm{NH}$ & T12 & $A$ \\
\hline 13 & 4 & 6 & $\mathrm{~F}$ & C & $\mathrm{NH}$ & T8 & $A$ \\
\hline 14 & 11 & 8 & $\mathrm{~F}$ & C & $\mathrm{NH}$ & T4 & $A$ \\
\hline 14 & 1 & 7 & $M$ & $\mathrm{AA}$ & $\mathrm{NH}$ & L1 & $A$ \\
\hline 15 & 2 & 8 & $M$ & AA & $\mathrm{NH}$ & T9 & A \\
\hline 15 & 4 & 9 & $\mathrm{~F}$ & C & $\mathrm{NH}$ & L3 & $\mathrm{D}$ \\
\hline 15 & 2 & 9 & $\mathrm{~F}$ & C & $\mathrm{NH}$ & $\mathrm{T} 10$ & D \\
\hline
\end{tabular}

Abbreviations: AA, African American; AIS, American Spinal Injury Association Impairment Scale; $\mathrm{C}$, Caucasian; F, female; H, Hispanic; M, male; NH, non-Hispanic; NL, neurological level according to International Standards for Neurological Impairment of Spinal Cord Injury (ISNCSCI); UN, unknown, unable to participate in the ISNCSCI examination.

aln years.
Table 2 Words and phrases that were repeatedly mispronounced andlor not understood by children

Words or phrases children could Coding Wordslphrases suggested by children

not read andlor comprehend

\begin{tabular}{|c|c|c|}
\hline Adaptive; adaptive device & $\mathrm{MJ} ; \mathrm{C}$ & $\begin{array}{l}\text { My new way; splints; things that } \\
\text { help me }\end{array}$ \\
\hline Artificial & $\mathrm{MJ} ; \mathrm{C}$ & Fake; make-believe; not real \\
\hline Assistance & C & Help \\
\hline BiPAP & MJ & \\
\hline Bladder & $\mathrm{MJ} ; \mathrm{C}$ & Holds my pee \\
\hline Blouse & I & Shirt; top \\
\hline Bra & I & Camie; undershirt \\
\hline Bowel/bowel management & MJ, C & Poop \\
\hline Bowel accident & MJ & $\begin{array}{l}\text { Pooped when I was not supposed to; } \\
\text { pooped at the wrong time; pooped in } \\
\text { my pants }\end{array}$ \\
\hline Condom catheter & MJ & \\
\hline Containers & C & \\
\hline Continence & $\mathrm{MJ} ; \mathrm{C}$ & \\
\hline Corset & MJ & \\
\hline Device & $\mathrm{C}$ & \\
\hline Electric aid & $\mathrm{MJ} ; \mathrm{C}$ & \\
\hline Equipment & $\mathrm{C}$ & Tool \\
\hline External drainage instrument & MJ & \\
\hline Fecal & $\mathrm{MJ} ; \mathrm{I} ; \mathrm{C}$ & Poop \\
\hline Genital & $\mathrm{MJ} ; \mathrm{C}$ & Private parts; private area \\
\hline Grooming & MJ & $\begin{array}{l}\text { Brush hair and wash face; fix myself } \\
\text { up; make myself look good }\end{array}$ \\
\hline Incontinence & $\mathrm{MJ} ; \mathrm{C}$ & \\
\hline Independent & $\mathrm{MJ} ; \mathrm{C}$ & All by myself; I can do it without help \\
\hline Indwelling catheter & MJ & Tube inside me that helps me pee \\
\hline Instrument & $\mathrm{C}$ & Tool \\
\hline Intermittent & C & On and off; in and out; not always \\
\hline Irregular & $\mathrm{C}$ & On and off \\
\hline Leg orthosis & MJ & Leg braces \\
\hline Lower body & V & Waist down, legs and private parts \\
\hline Meter & V & \\
\hline Management & $\mathrm{C}$ & \\
\hline Moderate & C & Kind of; so-so \\
\hline Orthosis & MJ & Brace \\
\hline Oxygen & MJ & Air \\
\hline Partial assistance & $\mathrm{MJ} ; \mathrm{C}$ & A little bit of help; I can do some of it \\
\hline PEEP & MJ & \\
\hline Permanent & $\mathrm{C}$ & Forever; not going to change \\
\hline Respiratory & $\mathrm{MJ} ; \mathrm{C}$ & Breathing \\
\hline Sanitary napkins & 1 & \\
\hline Seldom & $\mathrm{C}$ & $\begin{array}{l}\text { Not all of the time; not always; } \\
\text { sometimes }\end{array}$ \\
\hline Shawl & I & \\
\hline Stimulation for coughing & MJ & \\
\hline Stomach tube & MJ & \\
\hline Suppositories & MJ & $\begin{array}{l}\text { Medicine that helps me poop; medi- } \\
\text { cine for my butt }\end{array}$ \\
\hline Total assistance & $\mathrm{MJ} ; \mathrm{C}$ & $\begin{array}{l}\text { Cannot do it at all; someone else does } \\
\text { it for me }\end{array}$ \\
\hline Tracheal & MJ & windpipe; throat \\
\hline Tracheal Tube & MJ & Tube in the throat \\
\hline Trousers & C & Pants; jeans \\
\hline Upper body & $\mathrm{MJ} ; \mathrm{V}$ & $\begin{array}{l}\text { Waist up; belly button up; head, arms } \\
\text { and tummy }\end{array}$ \\
\hline Urine & MJ & Pee; pee-pee \\
\hline Ventilation & MJ & Help with breathing \\
\hline Walking aid & MJ;V & Crutches; walker \\
\hline Water tap & C & Faucet; sink \\
\hline
\end{tabular}

MJ refers to medical jargon. Word was too complex (C), vague (V) or irrelevant to children (I). 
Table 3 Sample of occupational and physical therapists for each of the three Delphi Survey Rounds

\begin{tabular}{|c|c|c|c|c|c|c|c|c|}
\hline Delphi Survey & Discipline & \multicolumn{4}{|c|}{ Years of experience $\mathrm{N}(\%)$} & \multicolumn{2}{|c|}{$\begin{array}{c}\text { Number (\%) therapist with } \\
\text { experience }\end{array}$} & Number (\%) experience with SCIM-II \\
\hline \multirow[t]{2}{*}{ Round 1} & ОТ $(N=34)$ & $4(11.8)$ & $7(20.6)$ & $7(20.6)$ & $16(47.1)$ & $30(88.2)$ & $30(88.2)$ & $13(38.2)$ \\
\hline & PT $(N=50)$ & $4(8)$ & $17(34)$ & $12(24)$ & $17(34)$ & $38(76)$ & $46(92)$ & $26(53.1)$ \\
\hline Round 2 & ОТ $(N=29)$ & $5(17.2)$ & $6(21)$ & $7(24.1)$ & $11(38)$ & $19(65.5)$ & $26(89.6)$ & $16(55.2)$ \\
\hline Round 3 & $\mathrm{PT}(N=33)$ & $2(6)$ & $13(39.4)$ & $8(24.2)$ & $10(30.3)$ & $22(66.7)$ & $32(97)$ & $23(69.7)$ \\
\hline
\end{tabular}

Abbreviation: $N$, number; OT, occupational therapist; PT, physical therapist.

description of the study and a link to the survey. Each of the iterative surveys was 'open' for a 3-week period. Therapists completed the surveys in anonymity.

For the first round of the Delphi survey, the exact wording and structure of the SCIM-III SR ${ }^{8}$ were exposed for critical review. Summary and descriptive statistics were used to calculate the frequency of yesino responses for each SCIM-III SR item and to determine the percent agreement among therapists on each of the three questions. Any item below $80 \%$ agreement was modified by replacing words and phrases with the ones suggested by the Delphi therapists and by children participating in the cognitive testing interviews. Modified items and response scales were again sent out for expert panel review. This process continued iteratively until $80 \%$ agreement was reached for each of the three questions, for each of the 17 SCIM-III SR items.

\section{STATEMENT OF ETHICS}

The Institutional Review Board approved this study.

\section{RESULTS}

\section{Cognitive testing}

As summarized in Table 1, 16 youths with SCI participated in cognitive testing. The mean time since injury was 4.4 years (range, 1-11 years). There were slightly more children with paraplegia $(62.5 \%)$ and complete injuries (56\%). The neurological characteristics of one child was unknown because of his inability to tolerate the standard examinations of the International Standards for Neurological Classification of Spinal Cord Injury (ISNCSCI). ${ }^{17}$

Table 2 lists the words that were repeatedly (in at least 10 interviews and within the same interview, multiple times) mispronounced and poorly understood. The majority of the words were coded as complex, vague or as medical jargon, whereas few were also coded as not relevant to children. We stopped enrollment after 16 interviews owing to the repetitive nature of the feedback and saturation of the data.

\section{Modified delphi technique}

Salient characteristics of the 84, 64 and 33 survey respondents who participated in each round of the Delphi are shown in Table 3. In round 1, 80\% agreement was reached for each of the 17 SCIM-III items for the question, 'Is this content appropriate for children?' Because consensus at or above $80 \%$ was achieved, this question was not asked in subsequent rounds.

Table 4 shows the results of each round for the additional two questions (Is this item written well for children and Is this response scale written well for children?). In round 1 , there was $80 \%$ agreement by both OT and PT that four items $(4,10,15,17)$ were written well for children. However, not one response scale reached the $80 \%$ requirement. Modifications, informed by feedback from Delphi round 1 and from cognitive testing interviews, were made to every SCIM-III item and response scale (Tables 5,6,7). For example, the original response scale for item 9 was eliminated and modified; the onus of scoring was shifted from the child to the person calculating the scores (Table 7). Youths and therapists all reported that children required different levels of help for tub and toilet transfers; hence, item 11 was modified into two questions (11A and 11B) (Table 7). As a way to preserve the original SCIM-III SR scoring, a single score for item 11 is calculated by assigning the lowest score given for $11 \mathrm{~A}$ and $11 \mathrm{~B}$ (see Supplementary material for scoring manual). For other items, medical jargon was eliminated, and preambles and definitions of words were embedded. As examples, for item 7 (Table 6), a preamble was added to convey to children what is meant by 'needing assistance with bowel management'; it reads: 'Help means having someone put medicine in my bottom or having someone put a finger in my bottom so that I can have a bowel movement (poop)....'. A preamble to item 5 (Table 6), 'I need a respiratory (tracheal) tube...' reads, 'Some kids with a spinal cord injury need help to breath, cough, and to clear their throat...'. With preambles, children understood items and were able to respond appropriately. Finally, for many of the SCIM-III SR items, we replaced complex words with simpler words that were suggested by the children (Table 4). Despite having had reached $80 \%$ agreement for three of the items in round 1 , due to the extensive modifications that were made, all items were exposed to round two of the Delphi Survey.

For round 2 (Table 4), 80\% of the OT agreed that each item and response scale was written well for children, except for the response scale for item 1 (69.6\% agreement). PT also reached agreement for all items, except for items $2 \mathrm{~A}(75.9 \%), 2 \mathrm{~B}(79.3 \%), 3 \mathrm{~A}(77.8 \%), 3 \mathrm{~B}$ $(74.1 \%)$ and $6(77.8 \%)$ and for all response scales except for $3(73.1 \%)$ and $6(69.2 \%)$. Because PT reached agreement for item 1 and the recommendations for modifications from OT would change the original intent of the item, we did not make further modifications. For items $2 \mathrm{~A}$ and $2 \mathrm{~B}$, the phrases 'using a water tap' (round 1) and 'turning on and off water' (round 2) were dropped. Therapists felt the phrase added a degree of complexity and that regardless of having or not having a SCI children usually have help with this task. For items $3 \mathrm{~A}$ and $3 \mathrm{~B}$, the sentence structure and complexity of the items were simplified by moving the concept of 'easy- and hard-to-dress clothes' to the response scales. Despite not reaching $80 \%$ agreement by PT, Item 6, 'Do you need help with urination or how you pee?' was not modified because the recommendations were not appropriate for children beyond pre-school age ('Do you need help with going potty?'). The modified items and response scales were exposed to a third Delphi round with PT and achieved $80 \%$ agreement (Table 4).

\section{DISCUSSION}

In this study, we exposed the SCIM-III SR to formal cognitive testing with youths with SCI and to scrutiny by experienced OT and PT. Our findings informed modifications to every SCIM-III SR item and response scale, producing a pediatric version of the tool that we 
Table 4 Results of Modified Delphi Technique

\begin{tabular}{|c|c|c|c|c|c|c|}
\hline \multirow{2}{*}{$\begin{array}{l}\text { Question } \\
\text { Delphi round }\end{array}$} & \multicolumn{3}{|c|}{$\begin{array}{c}\text { 'Item is written well for } \\
\text { children' }\end{array}$} & \multicolumn{3}{|c|}{$\begin{array}{c}\text { 'Response scale is written } \\
\text { well for children' }\end{array}$} \\
\hline & 1 & $2^{a}$ & 3 & 1 & $2^{a}$ & 3 \\
\hline
\end{tabular}

\begin{tabular}{|c|c|c|c|c|c|c|}
\hline $\begin{array}{l}\text { N OT responders } \\
\text { SCIM Item }\end{array}$ & 34 & 29 & & 34 & 29 & \\
\hline 1 & 94.7 & 96 & & 50 & $69.6^{\mathrm{b}}$ & \\
\hline $2 \mathrm{~A}$ & 73.3 & 80 & & 50 & 85.7 & \\
\hline $2 B$ & 68.4 & 85.7 & & 52.6 & 85.7 & \\
\hline $3 \mathrm{~A}$ & 47.5 & 80 & & 44.4 & 90 & \\
\hline $3 B$ & 52.6 & 84.2 & & 47.4 & 80 & \\
\hline 4 & 78.9 & 100 & & 57.9 & 95 & \\
\hline 5 & 84.2 & 100 & & 50 & 100 & \\
\hline 6 & 63.2 & 100 & & 38.9 & 90 & \\
\hline 7 & 82.4 & 100 & & 68.4 & 89.5 & \\
\hline 8 & 63.2 & 84.2 & & 61.1 & 94.1 & \\
\hline 9 & 52.9 & 89.5 & & 72.2 & c & \\
\hline 10 & 100 & 100 & & 66.7 & 94.7 & \\
\hline 11 & 78.9 & NA & NA & 44.4 & NA & NA \\
\hline $11 A^{d}$ & NA & 88.9 & & NA & 94.7 & \\
\hline $11 \mathrm{~B}^{\mathrm{d}}$ & NA & 87.5 & & NA & 94.7 & \\
\hline 12 & 89.5 & 89.5 & & 50 & 89.5 & \\
\hline 13 & 26.3 & 100 & & 50 & 89.5 & \\
\hline 14 & 73.7 & 100 & & 50 & 89.5 & \\
\hline 15 & 100 & 94,8 & & 84.2 & & \\
\hline 16 & 94.7 & 89.5 & & 55.6 & 100 & \\
\hline 17 & 100 & 94.7 & & 77.8 & 100 & \\
\hline N PT responders & 50 & 35 & 33 & 50 & 35 & 33 \\
\hline \multicolumn{7}{|l|}{ ScIM item } \\
\hline 1 & 79.4 & 93.3 & & 48.5 & 82.8 & \\
\hline $2 \mathrm{~A}$ & 60.6 & 75.9 & 90.6 & 51.5 & 89.3 & \\
\hline $2 B$ & 67.7 & 79.3 & 100 & 51.5 & 89.3 & \\
\hline $3 \mathrm{~A}$ & 70.6 & 77.8 & 90.3 & 47.1 & 73.1 & 84.4 \\
\hline $3 B$ & 63.6 & 74.1 & 87.1 & 52.9 & 73.1 & 84.4 \\
\hline 4 & 58.8 & 96.3 & & 53.1 & 96.3 & \\
\hline 5 & 84.8 & 88.9 & & 38.2 & 85.2 & \\
\hline 6 & 67.6 & 77.8 & 83.9 & 38.2 & 69.2 & 93.3 \\
\hline 7 & 71.9 & 96.3 & & 48.5 & 81.5 & \\
\hline 8 & 57.6 & 88.9 & & 54.5 & 85.2 & \\
\hline 9 & 70.6 & 88.9 & & 75 & c & \\
\hline 10 & 81.8 & 88.9 & & 51.5 & 92.6 & \\
\hline 11 & 82.4 & NA & NA & 49.2 & NA & NA \\
\hline $11 \mathrm{~A}^{\mathrm{d}}$ & NA & 88.9 & & NA & 92.6 & \\
\hline $11 \mathrm{~B}^{\mathrm{d}}$ & NA & 88.9 & & NA & 92.6 & \\
\hline 12 & 75.8 & 96.3 & & 44.4 & 80.8 & \\
\hline 13 & 47.1 & 92.6 & & 44.1 & 80.8 & \\
\hline 14 & 45.5 & 96.3 & & 44.1 & 80.8 & \\
\hline 15 & 87.5 & 88.5 & & 54.5 & 92.3 & \\
\hline 16 & 65.6 & 92.3 & & 43.3 & 84 & \\
\hline 17 & 81.8 & 88.5 & & 60.6 & 96 & \\
\hline
\end{tabular}

Abbreviations: $\mathrm{N}$, number of responders; OT, occupational therapists; PT, physical therapists. The original SCIM item 11 was dropped from round 2 and 3 (NA, not applicable).

a 2 due to the extensive changes that were made to each item following round 1 analysis.

b $80 \%$ agreement for the response scale for item 1 was not reached among OT; the item was not put out for round 3 as $>80 \%$ agreement was reached among PT, and changes requested by OT would change the original SCIM item intent.

${ }^{c} O n$ the basis of round 1 feedback, the response scale for item 9 was changed from words to a check box and was not exposed to round 2 or 3 .

dAfter round 1 , item 11 was divided into two parts, $11 \mathrm{~A}$ and $11 \mathrm{~B} ; 11 \mathrm{~A}$ and $11 \mathrm{~B}$ were exposed to round 2 . formally refer to as the SCIM-III SR-Youth (SCIM-III SR-Y) (Supplementary Appendix A). Although the wording of the SCIM-III SR-Y is different from those in the SCIM-III SR, modifications were carefully made as to avoid changing the original intent and scoring of any item. Preserving the item intent and the scoring was a priority so that scores can be compared, regardless of the version used (pediatric or adult); the comparison of summed scores between pediatric and adult versions requires further testing. Some modifications made scoring more difficult for the person interpreting the questionnaire. As a way to ease the burden of scoring and interpretation, we developed a SCIM-III SR-Y manual that shows each item and response scale and that provides the rationale and steps for scoring (see Supplementary Material).

Young children are capable of reporting on their own health status, ${ }^{18}$ assuming that the items and response scales are written with clarity, simplicity and minimal cognitive burden. ${ }^{19}$ We previously showed that youths with SCI as young as age 8 were able to understand and respond to questions. ${ }^{13}$ A fundamental problem with the SCIM-III SR was that youths did not understand the majority of the words and phrases. Comprehension problems with single words and small phrases were easily addressed by replacing them with words children suggested. Engaging children to evaluate reading and comprehension of items on patient reported outcome instruments, as has been done in this study, is essential prior to using them in research or practice. ${ }^{19}$

Two other problems encountered by children when reading and responding to the SCIM-III SR were vagueness of terminology and unfamiliarity with medical jargon. Even though the youths in this study had been injured for approximately $4 \frac{1}{2}$ years, they were unfamiliar with the meaning of the medical words in the SCIM-III SR. As a way to eliminate medical jargon and provide clarity, preambles enabled children to understand and appropriately respond to items that asked about complex health situations.

We did not anticipate how similar the cognitive testing results would be among participants. On the basis of our prior work ${ }^{13,14}$ and published literature, ${ }^{19}$ we estimated that we would need to perform cognitive testing interviews with at least five subjects of various ages to understand how children of different ages responded to the SCIM-III SR. In this study, the same words and phrases were repeatedly problematic, and youths' suggestions for change were relatively consistent across the ages. As we reached data saturation with 16 subjects, we stopped then.

An important finding from round 1 of the Delphi was that therapists agreed that the content of the SCIM-III SR was relevant to children, and thus no items were dropped. However, three rounds were needed before therapists agreed with the remaining two questions, ('Is this item written well?' and 'Is this response scale written well?'). Feedback from therapists was similar to what was garnered from the cognitive interviews and included recommendations to simplify the items and response scales, reduce the complexity and difficulty of words and phrases and eliminate medical jargon. The therapists also provided valuable feedback on how best to structure response scales in a way to minimize cognitive burden and increase relevancy to pediatric response. Several therapists provided feedback that the SCIM-III SR-Y should be designed as either a child- or a parent report.

There are limitations to this study. We did not perform cognitive testing with children aged 6 or younger and only enrolled one 7-yearold child. Thus, the SCIM-III SR-Y is not recommended for children younger than age 8 . Also, we did not enroll children with acute injuries who had little or no experience with performing activities with 
Table 5 SCIM-III SR and corresponding SCIM-III SR-Y with scoring: self-care domain

\section{SCIM-III SR self-care item and response scale}

\section{Eating and drinking}

A. I need artificial feeding or a stomach tube [0]

B. I need total assistance with eating/drinking [0]

C. I need partial assistance with eating/drinking or for putting on/taking off adaptive devices [1]

D. I eat/drink independently, but I need adaptive devices or assistance for cutting food, D. I do it by myself but use a splint or something on my hand to help me eat [2] pouring drinks, or opening containers [2]

E. I eat/drink independently without assistance or adaptive devices [3]

2A. Washing your upper body and head. Washing your upper body and head includes soaping and drying and using a water tap.
A. I need total assistance [0]
B. I need partial assistance [1]
C. I am independent but need adaptive devices or specific equipment (e.g. bars, chair) [2]
1. Do you need help with eating and drinking?
A. I eat nothing with my mouth [0]
B. I need help with all of it [0]
C. I need help with some of it [1]

SCIM-III SR-Y self-care item and response scale

D. I am independent and do not need adaptive devices or specific equipment [3]

E. I need help with cutting or pouring only [2]

F. I do it by myself without a splint or something on my hand to help me eat [3]

2A. When you take a bath or shower, do you need help with washing and drying your arms, chest, face and hair?

A. I need help with all of it [0]

B. I need help with some of it [1]

C. I do it myself with a bath chair and things to help me reach [2]

D. I do it myself without a bath chair and without things to help me reach [3]

2B. Washing your lower body. Washing your lower body includes soaping and drying and using a water tap.

A. I need total assistance [0]

B. I need partial assistance [1]

C. I am independent but need adaptive devices or specific equipment (e.g. bars, chair) [2]

D. I am independent and do not need adaptive devices or specific equipment [3]

$2 B$. When you take a bath or shower, do you need help with washing and drying your stomach, legs and feet?

A. I need help with all of it [0]

B. I need help with some of it [1]

[2]

D. I do it myself without a bath chair and without things to help me reach my back and legs [3]

3A. Dressing your upper body. Dressing the upper body includes putting on and taking off 3A. Do you need help with dressing your upper body (arms, chest and head) clothes like t-shirts, blouses, shirts, bras, shawls, or orthoses (e.g. arm splint, neck brace, including putting on and taking off $t$-shirts, sweaters, jackets and braces? corset). Easy to dress clothes are those without buttons, zippers or laces. Difficult to dress clothes are those with buttons, zippers or laces
A. I need total assistance [0]
B. I need partial assistance, even with easy to dress clothes [1]
C. I do not need assistance with easy to dress clothes, but I need adaptive devices or specific equipment [2]
D. I am independent with easy to dress clothes and only need assistance or adaptive
devices or a specific setting with difficult to dress clothes [3]
E. I am completely independent [4]

A. I need help with all of it [0]

B. I need help with some of it [1]

C. I do clothes without buttons, zippers, and laces myself but use splints or something on my hand to help me [2]

D. I only need help, a splint, or something on my hand to help me for clothes with buttons, zippers, or laces [3]

E. I do it by myself [4]

3B. Dressing your lower body. Dressing the lower body includes putting on and taking off clothes like shorts, trousers, shoes, socks, belts or orthoses (e.g. leg splint). Easy to dress clothes are those without buttons, zippers or laces. Difficult to dress clothes are those with buttons, zippers, or laces

A. I need total assistance [0]

B. I need partial assistance, even with easy to dress clothes [1]

C. I do not need assistance with easy to dress clothes, but I need adaptive devices or specific equipment [2]

D. I am independent with easy to dress clothes and only need assistance or adaptive devices or a specific setting with difficult to dress clothes [3]

E. I am completely independent [4]

3B. Do you need help with dressing your lower body (hips, legs and feet) including putting on and taking off pants, shorts, underwear, shoes, socks and braces?

A. I need help with all of it [0]

B. I need help with some of it [1]

C. I do clothes without buttons, zippers, and laces myself but use splints or something on my hand to help me [2]

D. I only need help, a splint, or something on my hand to help me for clothes with buttons, zippers, or laces [3]

E. I do it by myself [4]

4. Grooming. Please think about activities such as washing hands and face, brushing teeth, combing hair, shaving or applying make-up

A. I need total assistance [0]

B. I need partial assistance [1]

C. I am independent with adaptive devices [2]

D. I am independent without adaptive devices [3]

4. Do you need help with washing your hands and face, brushing your teeth and combing your hair?

A. I need help with all of it [0]

B. I need help with some of it [1]

C. I do not need help but do it with splints or something on my hand to help me [2]

D. I do it by myself without any help or a splint or something on my hand to help me [3] 
Table 6 SCIM-III SR and corresponding SCIM-III SR-Y with scoring: respiration and sphincter management domain

SCIM-III Respiration and Sphincter Management Item and Response Scale

5. Breathing

I need a respiratory (tracheal) tube...

A. as well as a permanent or from time to time assisted ventilation [0]

B. as well as extra oxygen and a lot of assistance in coughing or respiratory tube management [2]

C. as well as little assistance in coughing or respiratory tube management [4]

I do not need a respiratory (tracheal) tube...

D. but I need extra oxygen or a lot of assistance in coughing or a mask (e.g. PEEP) or assisted ventilation from time to time (e.g. BIPAP) [6]

E. and only little assistance or stimulation for coughing [8]

$\mathrm{F}$. and can breath and cough independently without any assistance or adaptive devices [10]

6. Bladder management. Please think about the way you empty your bladder

$6 \mathrm{~A}$. Use of an indwelling catheter

1. Yes $->$ Please go to question 7A [0]

2. No $->$ Please also answer questions $6 \mathrm{~B}$ and $6 \mathrm{C}[1]$

6B. Intermittent catheterization

1. I need total assistance [0]

2. I do it myself with assistance (self-catheterization) [1]

3. I do it myself without assistance (self-catheterization) [2]

4. I do not use it [3]

6C. Use of external drainage instruments (e.g. condom catheter, diapers, sanitary napkins)

1. I need total assistance for using them [0]

2. I need partial assistance for using them [1]

3. I use them without assistance [2]

4. I am continent with urine and do not use external drainage instruments [3]

\section{Bowel management}

7A. Do you need assistance with bowel management (e.g. for applying suppositories)?

1. Yes [0]

\section{No [1]}

7B. My bowel movements are

1. irregular or seldom (less than once in 3 days) [0]

2. Regular (once in 3 days or more) [1]

7C. Fecal incontinence (accidents) happens

1. Twice a month or more [0]

2. Once a month [1]

3. Not at all [2]
SCIM-III SR-Y Respiration and Sphincter Management Item and Response Scale

5. Some kids with a spinal cord injury need help to breath, cough and to clear their throat. Do you need help with breathing, coughing and clearing your throat?

A. I need a trach (tube in my throat) and vent (machine that breaths for me) all of the time [0]

B. I need a trach and a mask or tube in my nose for air and a lot of help to cough or clear my throat [2]

C. I need a trach and a mask or tube in my nose for air and a little help to cough or clear my throat [4]

D. I do not need a trach but I need a mask or tube in my nose for air or a lot of help to cough [6]

E. I do not need a trach but need a little help to cough [8]

F. I do it by myself [10]

6. Do you need help with urination, or how you pee?

A. I have a tube (foley) inside me all the time that lets me urinate (pee)

1. Yes [0]

2. No [1]

If you checked yes you are done with this questions and can move to 7

If you checked no, please check what best matches you in section $B$ and $C$

B. A cath (tube) is put inside me when I need to urinate (pee) and taken out when I am done

1. I need help with all of it [0]

2. I need help with some of it [1]

3. I do it by myself [2]

4. I do not urinate (pee) like this [3]

C. Putting on and taking off a pull up, diaper, or something else to keep my clothes from getting wet

1. I need help with all of it [0]

2. I need help with some of it [1]

3. I do it by myself [2]

4. I do not wear a pull up, diaper, or something to keep my clothes from getting wet [3]

7. Do you need help with bowel movements, or how you poop?

Check what best matches you in section $A, B$, and $C$ A.

1. Help means having someone put medicine in my bottom or having someone put a finger in my bottom so that I can have a bowel movement (poop). I need help with having a bowel movement (poop). [0]

2. I do not need help with having a bowel movement

B. I have a bowel movement (poop)

1. One time a week [0]

2. Almost every day or two [1]

C. Bowel (poop) accidents happen

1. A lot [0]

2. Sometimes [1]

3. Never [2]

8. Using the toilet. Please think about the use of the toilet, cleaning your genital area 8. When you urinate (pee) and have a bowel movement (poop), do you need help and hands, putting on and taking off clothes, and the use of sanitary napkins or diapers A. I need total assistance [0]

B. I need partial assistance and cannot clean myself [1]

when you wipe your private area, wash your hands, and put on and take off clothes? A. I need help with all of it [0]

B. I need help with some of it and cannot wipe my private area [1]

C. I need partial assistance but can clean myself [2]

C. I need help with some of it but can wipe my private area [2]

D. I do not need assistance but I need adaptive devices (e.g. bars) or a special setting D. I do it by myself but with a splint or something on my hand to help me [4] (e.g. wheelchair accessible toilet) [4]

E. I do not need any assistance, adaptive devices, or a special setting [5]

E. I do it by myself without any help or a splint or something on my hand to help me [5] 
Table 7 SCIM-III SR and corresponding SCIM-III SR-Y with scoring: mobility domain

SCIM-III Mobility Item and Response Scale

9. How many of the following four activities can you perform without assistance or electrical aids: turning your upper body in bed, turning your lower body in bed, sitting up in bed and doing push ups in wheelchair (with or without adaptive devices)

A. None, I need assistance in all these activities [0]

B. One [2]

C. Two or three [4]

D. All of them [6]

\section{Transfers from the bed to the wheelchair}

A. I need total assistance [0]

B. I need partial assistance, supervision, or adaptive devices (e.g. sliding board) [1]

C. I do not need any assistance or adaptive devices [2]

D. I do not use a wheelchair [2]

\author{
11. Transfers from the wheelchair to the toilet/tub \\ A. I need total assistance [0] \\ B. I need partial assistance, supervision, or adaptive devices (e.g. grab-bars) [1] \\ C. I do not need any assistance or adaptive devices [2] \\ D. I do not use a wheelchair [2]
}

SCIM-III SR-Y Mobility Item and Response Scale

9. Check the ones you do by yourself without help

A. Rolling my upper body (arms, chest, head) in bed

B. Rolling my lower body (hips, legs, feet) in bed

C. Sitting up in bed

D. Doing a wheelchair push up

Add up the number of checked responses and score as follows: None [0],

One [2], Two or three [4], All [6]

10. Do you need help going from the bed to your wheelchair?

A. I need help with all of it [0]

B. I need help with some of it or someone to be with me [1]

C. I do it by myself but with a transfer board [1]

D. I do it by myself without a transfer board [2]

E. I do not use a wheelchair [2]

11A. Do you need help going from your wheelchair to the toilet?

A. I need help with all of it [0]

B. I need help with some of it or someone to be with me [1]

C. I do it by myself but with a transfer board [1]

D. I do it by myself without a transfer board [2]

E. I do not use a wheelchair [2]

11B. Do you need help going from your wheelchair to the tub?

A. I need help with all of it [0]

B. I need help with some of it or someone to be with me [1]

C. I do it by myself but with a transfer board [1]

D. I do it by myself without a transfer board [2]

E. I do not use a wheelchair [2]

12. Do you need help moving short distances, such as inside your house or classroom?

I use a wheelchair to move around and

A. I always need help to move my wheelchair [0]

A. I need total assistance [0]

B. I need an electric wheelchair or partial assistance to operate a manual wheelchair [1]

C. I am independent in a manual wheelchair [2]

I walk indoors and I

D. need supervision while walking (with or without walking aids) [3]

E. walk with a walking frame or crutches, swinging forward with both feet at a time [4]

F. walk with crutches or two canes, setting one foot before the other [5]

G. walk with one cane [6]

H. walk with a leg orthosis(es) only (e.g. leg splint) [7]

I. walk without walking aids [8]

\section{Moving around moderate distances (10 to 100 meters)}

I use a wheelchair. To move around

A. I need total assistance [0]

B. I need an electric wheelchair or partial assistance to operate a manual wheelchair [1]

C. I am independent in a manual wheelchair [2]

I walk moderate distances and I

D. need supervision while walking (with or without walking aids) [3]

E. walk with a walking frame or crutches, swinging forward with both feet at a time [4]

F. walk with crutches or two canes, setting one foot before the other [5]

G. walk with one cane [6]

H. walk with a leg orthosis(es) only (e.g. leg splint) [7]

I. walk without walking aids [8]
B. I need a power wheelchair or some help to move my manual wheelchair [1] C. I do not need a power wheelchair and I do not need help to move my manual wheelchair [2]

I walk indoors and

D. Someone is always with me [3]

E. I walk with a walker or crutches by swinging both legs and feet together [4]

F. I walk with a walker or crutches by moving one foot forward at a time [5]

G. I walk with one crutch [6]

$\mathrm{H}$. I walk with braces on my legs and do not need a walker or crutches [7]

I. I walk with nothing to help me [8]

13. Do you need help moving medium distances such as down a school hallway or in a gymnasium?

I use a wheelchair to move around and

A. I always need help to move my wheelchair [0]

B. I need a power wheelchair or some help to move my manual wheelchair [1]

C. I do not need a power wheelchair and I do not need help to move my manual wheelchair [2]

I walk medium distances and

D. Someone is always with me [3]

E. I walk with a walker or crutches by swinging both legs and feet together [4]

F. I walk with a walker or crutches by moving one foot forward at a time [5]

G. I walk with one crutch [6]

$\mathrm{H}$. I walk with braces on my legs and do not need a walker or crutches [7]

I. I walk with nothing to help me [8] 
Table 7 (Continued)

SCIM-III Mobility Item and Response Scale

14. Moving around outdoors for more than 100 meters

I use a wheelchair. To move around

A. I need total assistance [0]

B. I need an electric wheelchair or partial assistance to operate a manual wheelchair [1]

C. I am independent in a manual wheelchair [2]

I walk more than 100 meters and I

D. need supervision while walking (with or without walking aids) [3]

E. walk with a walking frame or crutches, swinging forward with both feet at a time [4]

F. walk with crutches or two canes, setting one foot before the other [5]

G. walk with one cane [6]

H. walk with a leg orthosis(es) only (e.g. leg splint) [7]

I. walk without walking aids [8]

\section{Going up or down stairs}

A. I am unable to go up and down stairs [0]

I can go up and down at least 3 steps

B. but only with assistance or supervision [1]

C. but only with devices (e.g. handrail, crutch, or cane) [2]

D. without any assistance, supervision, or devices [3]
SCIM-III SR-Y Mobility Item and Response Scale

14. Do you need help moving longer distances outside such as around the block or at a shopping center?

I use a wheelchair to move around and

A. I always need help to move my wheelchair [0]

B. I need a power wheelchair or some help to move my manual wheelchair [1] C. I do not need a power wheelchair and I do not need help to move my manual wheelchair [2]

I walk longer distances outside and

D. Someone is always with me [3]

E. I walk with a walker or crutches by swinging both legs and feet together [4]

F. I walk with a walker or crutches by moving one foot forward at a time [5]

G. I walk with one crutch [6]

$\mathrm{H}$. I walk with braces on my legs and do not need a walker or crutches [7]

I. I walk with nothing to help me [8]

15. When standing, can you walk up or down steps?

A. I cannot go up or down steps [0]

B. I can go up and down 3 steps with help or if someone is with me [1]

C. I can go up and down 3 steps holding on to a railing or wall, or with crutches [2]

D. I can go up and down 3 steps by myself [3]

16. Transfers from the wheelchair into the car. Transfers include also putting the wheelchair 16. Do you need help going from your wheelchair into the car? into and taking it out of the car

A. I need total assistance [0]

B. I need partial assistance, supervision, or adaptive devices [1]

C. I do not need any assistance or adaptive devices [2]

D. I do not use a wheelchair [2]
A. I need help with all of it [0]

B. I need help with some of it or someone with me [1]

C. I do it myself with a transfer board [1]

D. I do it myself without a transfer board [2]

E. I do not use a wheelchair [2]

17. Do you need help to move from the floor to the wheelchair?

A. I need help [0]

B. I do not need any help [1]

C. I do not use a wheelchair [1] having a SCI. Thus, children with new injuries may not interpret or respond to SCIM-III SR items in the same way as found in our sample. Although some therapists may have participated in all three Delphi rounds, others may have participated in only one or two; likewise, therapists did not have to participate in the first round in order to participate in subsequent rounds. Engaging the same therapists in each of the three rounds may have been more systematic but would have also prevented input from therapists in the field who have rich experiences. We choose to be inclusive in an attempt to solicit feedback from a broad range of perspectives.

This study involved the initial validation of the SCIM-III SR-Y by examining face and content validity. We did not evaluate concurrent validity, responsiveness or reliability. We also take heed to the recommendation that the SCIM-III SR-Y should also be considered for parent report. As such, work is planned.

Finally, regardless of living with or without a chronic condition, children develop independence through a natural developmental process, which varies greatly. As a way to facilitate interpretation of the SCIM-III SR-Y, work is planned to establish norm references for typically developing children and for children with SCI.

\section{CONCLUSION}

The SCIM-III SR-Y is the pediatric version of the SCIM-III SR and can be administered to children aged 8 and older. Because the scoring algorithm was not modified, scores from the SCIM-III SR-Y can be compared with the SCIM-III SR enabling longitudinal monitoring across the life span and inclusion of children in clinical trials.

\section{DATA ARCHIVING}

There were no data to deposit.

\section{CONFLICT OF INTEREST}

The authors declare no conflict of interest.

\section{ACKNOWLEDGEMENTS}

We acknowledge the Physical and Occupational Therapy who participated in the surveys unnamed; their collective expertize greatly informed the development of the SCIM-III SR-Y. The study was funded by the Craig H Neilsen Foundation, Spinal Cord Injury Research on the Translation Spectrum, Senior Research Award \#282592 (Mulcahey, PI). 
1 Catz A, Itzkovich M, Agranov E, Ring H, Tamir A. SCIM-Spinal Cord Independence Measure: a new disability scale for patients with spinal cord lesions. Spinal Cord 1997; 35: $850-856$

2 Anderson KD, Aito S, Atkins M, Biering-Sorensen F, Charlifue S, Curt A et al. Functional recovery measures for spinal cord measures for spinal cord injury: an evidence based review of clinical practice and research. J Spinal Cord Med 2008; 31: 133-144.

3 Itzkovich M, Gelernter I, Biering-Sorenson F, Weeks C, Laramee MT, Craven BC et al. The spinal cord independence measure (SCIM) version III: reliability and validity in a multi-center international study. Disabil Rehabil 2007; 29: 1926-1933.

4 Bluvshtein V, Front L, Itzkovich M, Aidinoff E, Gelernter I, Hart J et al. SCIM III is reliable and valid in a separate analysis for traumatic spinal cord lesions. Spinal Cord 2011; 49: 292-296.

5 Anderson KD, Acuff ME, Arp BG, Backus D, Chun S, Fisher K et al. United states (US) multi-center study to assess the validity and reliability of the spinal cord independence measure (SCIM III). Spinal Cord 2011; 49: 88-885.

6 Scivolette G, Tamburella F, Laurenza L, Molinari M. The spinal cord independence measure: how much change is clinically significant for spinal cord injury subjects. Disabil Rehabil 2013; 35: 1808-1813.

7 Aidinoff E, Front L, Itzkovich M, Bluvshtein V, Gelernter I, Hart J et al. Expected spinal cord independence measure, third version, scores for various neurological levels after complete spinal cord lesions. Spinal Cord 2011; 49: 893-896.

8 Fekete C, Eriks-Hoogland I, Baumberger M, Catz A, Itzkovich M, Luthi H, et al. Development and validation of a self-report version of the spinal independence measure (SCIM III). Spinal Cord 2013; 51: 40-47.

9 Vogel LC, Betz RR, Mulcahey MJ. Spinal cord injuries in children and adolescents. In: Verhaagen J, McDonald J (eds). Handbook of Clinical Neurology. Elsevier, 2012, pp 138-148.
10 Merenda L, Dean G. Neurogenic bladder and bowel: assessment, management and outcomes. In: Vogel L, Zebracki K, Betz R, Mulcahey MJ (eds). Spinal Cord Injury $n$ the Child and Young Adult. McKeith Press: London, UK, Chapter 11, 2014; pp 153-166.

11 Dumas H, Haley SM, Boyce M, Peters C, Mulcahey MJ. Self-reported measures of physical function for children with spinal cord injury: a review of current tools and an option for the future. Dev Neurorehabil 2009; 12: 113-118.

12 Drennan J. Cognitive interviewing: verbal data in the design and pretesting of questionnaires. J Adv Nurs 2003; 42: 57-63.

13 Mulcahey MJ, Calhoun C, Riley A, Haley S. Children's reports of activity and participation after sustaining spinal cord injury: a cognitive interviewing study. Dev Neurorehabil 2009; 12: 191-200.

14 Mulcahey MJ, Samdani A, Chafetz R, Santangelo AM, Merenda L, Costello K, et al. Cognitive testing of the spinal appearance questionnaire with typically developing youth and youth with idiopathic scoliosis. J Pediatr Orthop 2011; 31: 661-667.

15 Van Somerson M, Barnard YF, Sandberg JA. The Thin Aloud Method: A Practical Guide tom Modelliing Cogntive Processes. Academic Press: San Diego, CA, USA, 1994.

16 Dalkey NC. The Delphi method: an experimental application of group opinion In: Dalkey NC, DI Rourke R, Lewis, Snyder D (eds). Studies in the Quality of Life. Lexington Books: Lexington, MA, USA.

17 Mulcahey MJ, Vogel L, Betz R, Samdani A, Chafetz R, Gaughan J. The international standards for neurological classification of spinal cord injury: psychometric evaluation and guidelines for use with children and youth. Phys Med Rehabil 2011; 92: 1264-1269.

18 Riley AW. Evidence that school-age children can self-report on their own health. Ambul Pediatr 2004; 4: 371-376.

19 Matza LS, Patrick DL, Riley AW, Alexander JJ, Rajmil L, Pleil AM et al. Pediatric patient reported outcome instruments for research to support edical product labeling: report of the ISPOR PRO good research medical practices for the assessment of children and adolescent task force. Value Health 2013; 16: 461-479.

Supplementary Information accompanies this paper on the Spinal Cord website (http://www.nature.com/sc) 